\title{
Urgensi Sikap Dermawan Menurut Hadis
}

\author{
Rena Ajeng Triani \\ Department of Hadith Science, Faculty of Usuluddin \\ UIN Sunan Gunung Djati Bandung \\ renaajeng99@gmail.com
}

\begin{abstract}
The purpose of this study is to discuss the urgency of generosity in the hadith. This research method uses a qualitative type through literature study with content analysis. The results and discussion of this study include general views on generosity, hadith about generosity, and the application of generosity according to hadith. This study concludes that Islam is a perfect religion. Not only regulating habluminallah but also regulating habluminannas, which must be done properly, correctly and in balance. One of the teachings of Islam that Allah has commanded to his people is caring and giving. Confession of the truth of a person's faith can be measured by his giving behavior. Giving is not a bad deed, but on the contrary, it is a commendable act. The generous person is close to Allah, close to heaven, close to humans, and far from hell.
\end{abstract}

Keywords: Alms, Generous, Hadith

Abstrak
Tujuan penelitian ini membahas urgensi sikap dermawan dalam
hadis. Metode penelitian ini menggunakan jenis kualitatif melalui
studi pustaka dengan analisis isi. Hasil dan pembahasan
penelitian ini meliputi pandangan umum tentang
kedermawanan, hadis tentang kedermawanan, dan penerapan
sikap dermawan menurut hadis. Penelitian ini menyimpulkan
bahwa Islam adalah agama yang sempurna. Tak hanya mengatur
habluminallah tetapi juga mengatur habluminannas, yang harus
dilakukan secara baik, benar dan seimbang. Salah satu ajaran
Islam yang diperintahkan Allah kepada umatnya adalah peduli
dan berderma. Pengakuan kebenaran iman seseorang dapat
diukur dari perilaku berdermanya. Berderma itu bukan
perbuatan buruk, melainkan sebaliknya yakni perbuatan terpuji.
Orang dermawan itu dekat dengan Allah, dekat dengan surga,
dekat dengan manusia, dan jauh dari neraka.

Kata kunci: Dermawan, Hadis, Sedekah 
Jurnal Riset Agama, Volume 1, Nomor 1 (April 2021): 177-186

Rena Ajeng Triani/Urgensi Sikap Dermawan Menurut Hadis

\section{Pendahuluan}

Di antara wujud nyata dari rasa kepedulian terhadap orang lain adalah senang berbagi atas hak kepemilikan seseorang kepada orang lain. Kepemilikan itu pada hakikatnya bersifat relatif, mengingat kepemilikan itu mutlak hanya milik Allah. Pada dasarnya manusia diberikan amanat untuk memanfaatkan apa yang dimilikinya untuk memenuhi apa yang diperlukannya, dan dianjurkan untuk tidak lupa berderma. Keadaan jiwa seseorang yang suka berderma biasanya mempunyai rasa simpati dan empati yang tinggi terhadap oranglain juga mudah merasa iba. Keimanan yang matang tercermin dalam perilaku kepedulian seseorang terhadap oranglain. Namun dalam hal pemberian, tidak hanya terbatas pada hal yang bersifat materil. Tetapi lebih dari itu, mencakup semua perbuatan yang bersifat fisik atau non fisik. Maka dari itu, menjadi hal yang sangat penting dalam menjalani kehidupan ini menjadi seorang yang dermawan, karena orang yang suka berderma, pada dasarnya telah menanamkan kebaikan untuk kehidupan di masa yang akan datang. Dalam hubungan sosial, setidaknya hal ini diharapkan dapat menjadi suatu proses bagi terhapusnya kemiskinan, dan meningkatkan pertumbuhan ekonomi (Naya, 2014).

Sejumlah pakar telah melakukan penelitian tentang hal tersebut sebagaimana dalam tinjauan pustaka ini. Antara lain Naya, F (2014), "Sakha' dalam Perspektif Hadis," Penerbit Fakultas Syariah dan Ekonomi Islam IAIN Ambon. Artikel ini menggunakan metode penelitian deskriptif dengan pendekatan studi kepustakaan yakni mengumpulkan hadis-hadis berkenaan dengan urgensi sikap dermawan. Hasil dan pembahasan dari artikel ini adalah menjelaskan tema-tema pokok hadis berkenaan dengan menjaga diri dari meminta-minta, mengeluarkan zakat, dan membantu sesama yang sedang membutuhkan (Naya, 2014). Maulana, F (2016), "Penanaman Nilai-nilai Kedermawanan dalam Kegiatan Organisasi IPNU di Ranting Sampang Kecamatan Sampang Kabupaten Cilacap," Penerbit Fakultas Tarbiyah dan Ilmu Keguruan IAIN Purwokerto. Artikel ini menggunakan metode deskriptif analisis yakni mendeskripsikan atau memberi gambaran tentang penanaman nilai-nilai kedermawanan melalui data atau sampel yang telah dikumpulkan. Hasil dan pembahasan artikel ini adalah memaparkan penanaman nilai-nilai kedermawanan yang ada dalam kegiatan organisasi IPNU di Ranting Sampang yang berkaitan dengan akhlakul karimah, khususnya penanaman sikap kedermawanan melalui beberapa metode dan cara sehingga menghasilkan kebiasaan mengisi infaq dan kas (Maulana, 2016). Al-Asy'ari, A (2018), “Peningkatan Sikap Dermawan dalam Perspektif Imam Al-Ghazali," Penerbit Jurusan Tasawuf dan Psikoterapi Fakultas Ilmu Ushuluddin dan Humaniora UIN Walisongo Semarang. Artikel ini menggunakan pendekatan kualitatif dengan pendekatan perspektif Al-Gazali. Hasil dan pembahasan artikel ini 
adalah sikap dermawan menurut Imam Al-Ghazali pada zaman sekarang adalah kebahagiaan akan tercapai melalui keutamaan jiwa seperti ilmu akhlak yang baik. Untuk memperoleh sikap dermawan di dunia mulailah dengan memiliki akhlak yang mulia (Al-Asy'ari, 2018).

Berbagai penelitian terdahulu berharga bagi penyusunan kerangka berpikir penelitian ini. Dermawan merupakan perilaku mulia seseorang terhadap sesame dengan memberikan sebagian harta yang dimiliki untuk kepentingan orang lain tanpa keterpaksaan dan juga sebagai rasa syukur terhadap Allah swt. atas berbagai karunia-Nya (Al-Asy'ari, 2018). Kedermawanan yaitu memberikan sesuatu kepada orang lain tanpa mengharapkan imbalan sedikitpun dari yang diberi, melainkan sebagai rasa syukur kepada Allah swt. atas berbagai karunia yang telah diberikan (Naya, 2014). Pengakuan iman yang benar dapat terukur dari perilaku suka bersedekah (Nofiaturrahmah, 2018). Hadis-hadis Rasulullah SAW. mengenai kedermawanan ini di antaranya berkenaan dengan soal memberi kepada orang lain tanpa mengharapkan imbalan. Hadis tentang kedermawanan di antaranya diriwayatkan oleh Bukhari, Al-Nasa'i, dan AlDarimi. Berderma itu bukan perbuatan buruk, melainkan sebaliknya yakni perbuatan terpuji, maka hadis-hadis mengenai kedermawanan adalah bernilai maqbul (Naya, 2014). Penanaman sikap dermawan bisa melalui metode pembiasaan, keteladanan, serta melalui pendekatan perilaku sosial dan perkembangan moral kognitif. Serta strategi yang digunakan melalui kegiatan rutin, spontan, keteladanan dan pengkondisian (Nofiaturrahmah, 2018). Diperlukan peningkatan sikap dermawan melalui tiga tingkatan yaitu as-sakha, al-karam dan al-ittsar yang disertai oleh sikap pendukung seperti kebaikan akhlak, mengetahui dan menghindari penyakit hati dan mencari obatnya, kenali aib diri sendiri, hidup zuhud dan mengetahui kandungan nilai-nilai yang ada pada sikap dermawan kemudian diaplikasikan melalui zakat, infaq dan șodaqah (Al-Asy'ari, 2018). Penerapan sikap kedermawanan bisa diwujudkan dalam bentuk zakat, infak, sedekah dan wakaf (Amar, 2017).

Berdasarkan paparan di atas, formula penelitian disusun, yaitu rumusan masalah penelitian, pertanyaan utama penelitian, dan tujuan penelitian (Darmalaksana W. , 2020). Rumusan masalah penelitian ini adalah terdapat ugensi sikap dermawan dalam hadis. Pertanyaan utama penelitian ini ialah bagaimana urgensi sikap dermawan dalam hadis. Sedangkan pertanyaan penelitian secara terperinci yakni bagaimana pandangan umum tentang kedermawanan, bagaimana hadis-hadis tentang kedermawanan, dan bagaimana penerapan sikap dermawan menurut hadis. Tujuan penelitian ini yaitu untuk membahas urgensi sikap dermawan dalam hadis. Penelitian ini diharapkan bermanfaat bagi pengayaan khazanah pengetahuan Islam. 
Jurnal Riset Agama, Volume 1, Nomor 1 (April 2021): 177-186

Rena Ajeng Triani/Urgensi Sikap Dermawan Menurut Hadis

\section{Metode Penelitian}

Penelitian ini merupakan jenis kualitatif melalui studi pustaka dengan analisis isi (Darmalaksana, 2020).

\section{Hasil dan Pembahasan Penelitian}

Hasil dan pembahasan penelitian di bawah ini.

\section{Pandangan Umum tentang Kedermawanan}

Kedermawanan berasal dari Bahasa Yunani yaitu Filantropi yang terdiri dari dua kata yaitu philein yang berarti cinta dan anthropos yang berarti manusia, adalah seseorang yang mencintai sesama manusia, sehingga menyumbangkan sesuatu yang dimilikinya berupa waktu, uang, dan tenaga untuk menolong orang lain. Filantropi berasal dari dunia Barat yang berarti kedermawanan. Kedermawanan berasal dari kata dermawan yang artinya orang yang suka memberikan derma atau pemurah hati. Kedermawanan adalah kebaikan hati seseorang terhadap orang lain. Kedermawanan merupakan suatu sikap memberikan harta kepada oranglain tanpa diminta haknya dan itu adalah salah satu sifat terpuji. Dermawan merupakan bagian dari ahlak mulia yang dapat miliki oleh seseorang melalui dua hal. Pertama, dapat dimiliki karena tabiat alami yang telah dikodratkan dan menjadi fitrah bagi setiap orang. Kedua, dapat dimilki melalui latihan, pembiasaan dan pengalaman (Maulana, 2016). Jika melihat orang yang sedang kesusahan atau membutuhkan bantuan, orang yang mempunyai sifat dermawan akan merasa senang jika bisa membantunya. Hidup seseorang akan lebih bahagia jika memiliki sifat yang dermawan, karena dengan kedermawanannya maka akan melapangkan dadanya. Dalam kamus lengkap bahasa Indonesia kata "dermawan" berarti memberikan sebagian harta yang dimiliki untuk kepentingan orang lain tanpa keterpaksaan. Secara sosial orang yang memiliki sifat dermawan akan disenangi banyak orang, sehingga orang pun senang jika bersama dengannya. Sedangkan kebalikan dari sifat dermawan adalah tamak. Orang yang tamak biasanya tidak disenangi orang, dan hidupnya tidak tenang. Cerminan perilaku mulia seseorang kepada Sang pencipta dan sesama terlihat pada sikap dermawannya. Orang yang rela berkorban dengan ikhlas di jalan Allah, selalu menolong dan memberi, baik dengan harta ataupun jiwa nya merupakan seseorang yang dermawan (Al-Asy'ari, 2018).

Islam merupakan agama yang sempurna. Tak hanya mengatur hubungan manusia dengan Allah (habluminallah) tetapi juga mengatur hubungan manusia dengan sesama manusia (habluminanas), yang harus dilakukan secara baik, benar dan seimbang. Sebagaimana harapan yang selalu dipinta oleh setiap kaum muslimin kepada Allah, semua itu dimaksudkan agar manusia dapat meraih kebahagiaan hidup di dunia dan 
akhirat nanti. Salah satu ajaran Islam yang diperintahkan Allah kepada umatnya adalah peduli dan berbagi. Ajaran itu tak hanya menjadi sebuah kebaikan, tetapi melekat dalam salah satu rukun Islam, yang wajib untuk dilaksanakan. Untuk bisa berbagi dan peduli, tidak cukup hanya landasan teologi saja yang menjadi basisnya tetapi juga landasan hukum yang jelas dan tegas, untuk dilaksanakan. Perintah untuk peduli dan berbagi ini dipraktekkan melalui kegiatan sedekah, infak, zakat, hibah, wakaf dan juga wasiat. Dengan demikian, ciri khas yang melekat pada seseorang yang mempunyai sifat dermawan yaitu adanya rasa peduli kepada sesama, rasa cinta ke sesama makhluk Allah, tidak merasa terpaksa dalam membantu orang yang sedang membutuhkan, baik membantu secara materi ataupun non materi. Kesadaran akan cinta dan kasih sayang terhadap sesama juga karena kewajiban agama menjadi landasan untuk melakukan itu semua. Sehingga, tidak ada rasa pamrih dan membeda-bedakan agama, ras dan golongan dalam melakukannya (Amar, 2017).

\section{Hadis tentang Kedermawanan}

Terdapat hadis Nabi Saw. berkenaan dengan kedermawanan dalam kitab Shahih Bukhari Nomor 2910:

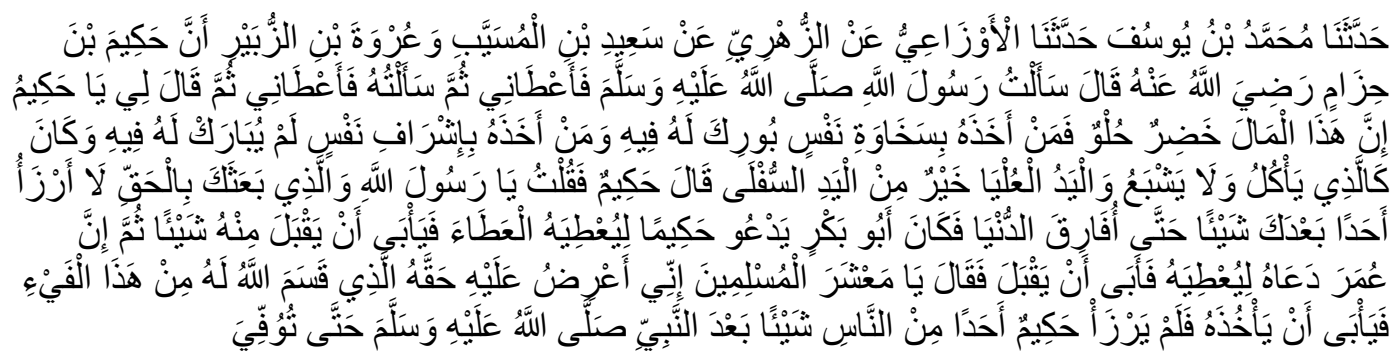

Telah bercerita kepada kami Muhammad bin Yusuf telah bercerita kepada kami Al Awza'iy dari Az Zuhriy dari Sa'id bin 'AbdullahlMusayyab dan 'Urwah bin Az Zubair bahwa Hakim bin Hizam radliallahu 'anhu berkata; 'Aku meminta sesuatu kepada Rasulullah Shallallahu'alaihiwasallam lalu Beliau memberikannya, kemudian aku meminta lagi dan Beliaupun kembali memberikannya lalu Beliau berkata kepadaku: "Wahai Hakim, harta itu hijau lagi manis, maka barangsiapa yang mencarinya untuk kedermawanan dirinya maka harta itu akan memberkahinya. Namun barangsiapa yang mencarinya untuk keserakahan (ambisius, tamak) maka harta itu tidak akan memberkahinya, seperti orang yang makan namun tidak kenyang. Tangan yang di atas lebih baik daripada tangan yang di bawah". Hakim berkata; "Lalu aku berkata (kepada Beliau); "Wahai Rasulullah, demi Dzat yang telah mengutusmu dengan benar, aku tidak akan mengurangi hak seorangpun (dengan meminta) setelah engkau hingga aku meninggalkan dunia ini". Suatu kali Abu Bakar pernah 
memanggil Hakim untuk diberikan sesuatu agar dia datang dan menerima pemberiannya. Kemudian 'Umar radliallahu 'anhu juga pernah memanggil Hakim untuk memberikan sesuatu namun Hakim tidak memenuhinya. Maka 'Umar radliallahu 'anhu berkata: "Wahai kaum Muslimin sekalian, sungguh aku pernah menawarkan kepadanya haknya dari harta fa'i ini (harta musuh tanpa peperangan) namun dia enggan untuk mengambilnya dan sungguh Hakim tidak pernah mengurangi hak (meminta) seorangpun setelah Rasulullah Shallallahu'alaihiwasallam hingga dia wafat."

Mula-mula dilakukan pencarian pada aplikasi hadis dengan kata kunci "Kedermawanan" hingga ditemukan hadis pada kitab Sahih Bukhari Nomor 2910.

Tabel 1 Daftar Rawi Sanad

\begin{tabular}{|c|c|c|c|c|c|c|c|}
\hline \multirow{2}{*}{$\begin{array}{l}\mathbf{N} \\
\mathbf{o}\end{array}$} & \multirow{2}{*}{$\begin{array}{l}\text { Rawi } \\
\text { Sanad }\end{array}$} & \multicolumn{2}{|c|}{$\begin{array}{c}\text { Lahir/Wafa } \\
t\end{array}$} & \multirow{2}{*}{ Negeri } & \multirow{2}{*}{ Kuniyah } & $\begin{array}{l}\text { Komentar } \\
\text { Ulama }\end{array}$ & \multirow{2}{*}{ Kalangan } \\
\hline & & $\mathbf{L}$ & W & & & \begin{tabular}{l|l}
- & + \\
\end{tabular} & \\
\hline 1 & $\begin{array}{l}\text { Hakin bin } \\
\text { Hizam bin } \\
\text { Khuwailid }\end{array}$ & & $54 \mathrm{H}$ & $\begin{array}{l}\text { Marur } \\
\text { Rawdz }\end{array}$ & Abu Khalid & $\begin{array}{l}\text { Sahaba } \\
\mathrm{t}\end{array}$ & Sahabat \\
\hline 2 & $\begin{array}{l}\text { Sa'id bin } \\
\text { Al- } \\
\text { Musayyab } \\
\text { bin Hazan }\end{array}$ & & $93 \mathrm{H}$ & $\begin{array}{l}\text { Madina } \\
\mathrm{h}\end{array}$ & $\begin{array}{l}\text { Abu } \\
\text { Muhamma } \\
\text { d }\end{array}$ & $\begin{array}{l}\text { Tsiqah } \\
\text { Ahli } \\
\text { fiqih }\end{array}$ & $\begin{array}{l}\text { Tabi'in } \\
\text { kalangan } \\
\text { tua }\end{array}$ \\
\hline 3 & $\begin{array}{l}\text { Muhamma } \\
\mathrm{d} \text { bin } \\
\text { Muslim bin } \\
\text { 'Ubaidillah }\end{array}$ & & $124 \mathrm{H}$ & $\begin{array}{l}\text { Madina } \\
\mathrm{h}\end{array}$ & Abu Bakar & $\begin{array}{l}\text { Faqih } \\
\text { hafidz } \\
\text { mutqin }\end{array}$ & $\begin{array}{l}\text { Tabi'ut } \\
\text { Tabi;in } \\
\text { kalangan } \\
\text { pertengaha } \\
\text { n }\end{array}$ \\
\hline 4 & $\begin{array}{l}\text { Abdur } \\
\text { Rahman } \\
\text { bin 'Amru } \\
\text { bin Abi } \\
\text { 'Amru }\end{array}$ & & $157 \mathrm{H}$ & Syam & Abu 'Amru & Tsiqah & $\begin{array}{l}\text { Tabi'ut } \\
\text { Tabi'in } \\
\text { kalangan } \\
\text { tua }\end{array}$ \\
\hline 5 & $\begin{array}{l}\text { Muhamma } \\
d \text { bin Yusuf } \\
\text { bin Waqid }\end{array}$ & & $212 \mathrm{H}$ & Syam & $\begin{array}{l}\text { Abu } \\
\text { ‘Abdullah }\end{array}$ & $\begin{array}{l}\text { Shalih } \\
\text { Tsiqah }\end{array}$ & $\begin{array}{l}\text { Tabi'ib } \\
\text { kalangan } \\
\text { biasa }\end{array}$ \\
\hline
\end{tabular}

Tabel 1 adalah daftar rawi dan sanad hadis riwayat Bukhari yang sedang diteliti. Tabel ini menggambarkan transmisi hadis dari periwayat pertama hingga akhir. Jika beberapa kriteria kesahihah telah dipenuhi maka derajat suatu hadis dianggap shahih. Jika hubungannya dengan sanad maka hadits tersebut harus bersambung sanadnya, sang perawi 
harus 'adil, dan sang perawi bersifat dhabit. Apabila berkaitan dengan matan hadits, maka hadits tersebut tidak mengandung 'illat (penyakit/cacat) ataupun syadz (kejanggalan). Berdasarkan informasi dari biografi perawi dan penilaian ulama kritikus hadis terhadap para perawi hadis dari masing-masing tingkatan (thabaqah) di atas semuanya adalah tsiqah. Di lengkapi dengan adanya indikasi kuat perjumpaan para perawi hadis tersebut dengan melihat terjadinya proses peneriman dan penyampaian hadis antara guru dengan murid (Naya, 2014).

Selain itu sebaran hadis ini juga berperan sebagai syahid dan mutabi. Syahid adalah hadis lain yang sejenis sedangkan mutabi adalah sanad lain (Darmalaksana, 2020). Di antaranya yaitu hadis Nomor 2555 dalam Kitab Sunan Al-Nasa'I dan hadis Nomor 2632 dalam Kitab Sunan Al-Darimi. Dalam hadis ini terdapat ketersambungan sanad hadis, maka dapat dikatakan bahwa hadis yang diriwayatkan oleh Hakim bin Hizam telah memenuhi kriteria kesahihan sanad hadis dan dapat dinyatakan sanad hadis tersebut adalah sahih (Naya, 2014).

Syarah dan maksud dari hadis di atas berbicara tentang sakha' dalam pengertian dermawan atau sifat kemurahan hati seseorang yang memberikan sesuatu yang kita miliki kepada orang lain tanpa mengharapkan imbalan atau balasan dari siapapun termasuk dari orang yang diberi atau yang meminta, melainkan semata-mata merupakan pengaplikasian rasa syukur kita kepada Allah atas berbagai karunia yang telah diberikan dan sekaligus sebagai upaya menghindarkan diri dari sikap dan perilaku tamak atau perilaku meminta-minta. Bahkan dalam hadis di atas dijelaskan, bahwa sesungguhnya harta itu hijau lagi manis, maka barangsiapa yang mencarinya untuk kedermawanan dirinya maka harta itu akan memberkahinya. Namun barangsiapa yang mencarinya untuk keserakahan maka harta itu tidak akan memberkahinya, seperti orang yang makan namun tidak kenyang. Jika decermati dari sabda Nabi Saw diatas, dapat disimpulkan bahwa "sesungguhnya harta itu hijau lagi manis," menunjukkan harta itu dapat tumbuh subur melimpah dan berkembang menjadi lebih banyak jika dikelola dengan baik, jujur dan amanah. Pesan lain yang juga bisa ditangkap dari hadis tersebut selain yang telah disampaikan adalah agar hendaknya umat Islam tidak mencari harta di dunia ini hanya untuk memperkaya diri sendiri, keluarga, dan golongannya sendiri, dan tidak diinfaqkan melainkan bagaimana dengan harta yang dimilikinya tersebut dapat dengan mudah untuk diberikan atau didermakan kepada orang lain tanpa harus diminta sekalipun. Islam sangat menaruh perhatian terhadap kebahagian manusia baik ketika hidup di dunia maupun di akhirat nanti, maka Islam memberikan solusi antisipatif dengan memperkenalkan terlebih dahulu medianya dalam bentuk sikap dan perilaku kedermawanan atau kelapangan atau keterbukaan hati untuk gemar berbagi dengan sesama manusia terhadap hak kepemilikan yang 
ada pada manusia itu sendiri. Karena sesungguhnya terdapat hak orang lain di balik kepemilikan sesuatu, berupa harta benda dan ilmu. Karena itu Islam memberikan tuntunan langsung lewat apa yang diparktekkan oleh Rasulullah Saw. dalam kehidupannya sehari-hari, agar ajaran yang mulia ini tidak hanya sebagai konsep belaka. Termasuk dalam hal ini adalah tindakan rasulullah terhadap sikap sahabatnya yang bernama Hakim bin Hizam di atas (Naya, 2014).

\section{Penerapan Sikap Dermawan menurut Hadis}

Kedermawanan merupakan perilaku baik terhadap orang lain yang berasal dari hati. Orang yang memiliki sifat suka memberi atau memberikan derma dengan hati yang senang merupakan arti dari kata dermawan. Kedermawanan merupakan sifat terpuji dengan memberikan harta kepada orang lain tanpa diminta haknya. Dermawan merupakan bagian dari akhlak mulia yang dapat dimiliki oleh seseorang melalui dua hal. Pertama, dapat dimiliki karena tabiat alami yang telah dikodratkan dan menjadi fitrah bagi setiap orang. Kedua, dapat dimiliki melalui latihan, pembiasaan dan pengalaman. Pada hadits Nabi yang diriwayatkan oleh Imam Bukhori dan Muslim Nabi Saw bersabda bahwa tiap-tiap muslim wajib bersedekah. Para sahabat tidak mengerti lantaran mereka mengira yang dimaksud bersedekah adalah memberikan benda-benda yang dimiliki, padahal sebagian sahabat ada yang tidak memiliki harta benda. Karena itu, para sahabat bertanya, bagaimana kalau tidak memiliki sesuatu? Mendapat pertanyaan semacam ini, Rasulullah Saw. menjawab bahwa bekerja dengan ketrampilan yang dimiliki untuk kemanfaatan dirinya sudah dapat disebut bersedekah. Sahabat bertanya lagi, bagaimana kalau ia tidak mampu? Nabi Saw. menjawab bahwa menolong orang yang sedang teraniyaya termasuk sedekah. Sahabat bertanya lagi, bagaimana kalau tidak bisa menolong? Nabi Saw. menjawab menyuruh orang untuk berbuat baik (ma'ruf) termasuk sedekah. Bagaimana kalau masih tidak bisa melakukannya? Nabi Saw. menjawab bahwa mencegah diri dari berbuat kejahatan itu juga termasuk bersedekah (Zuhdy, 2017). Orang yang dermawan akan mendapatkan banyak keuntungan, baik di dunia ataupun di akhirat nanti. Keuntungan di dunia seperti disenangi banyak orang, mempunyai hubungan baik dengan orang-orang di sekitar, selain itu masyarakat juga akan sangat terbantu oleh sikap kedermawanan seseorang. Orang yang gemar mensedekahkan hartanya di jalan Allah tidak akan mengalami kerugian sedikitpun. Sebaliknya orang yang pelit akan dekat dengan neraka, jauh dari manusia, jauh dari Allah swt. dan jauh dari surga. Dan dia hanya akan mendapatkan kerugian di dunia dan di akhirat nanti. Sebagaimana terdapat dalam hadis yang diriwayatkan oleh AtTirmidzi: 


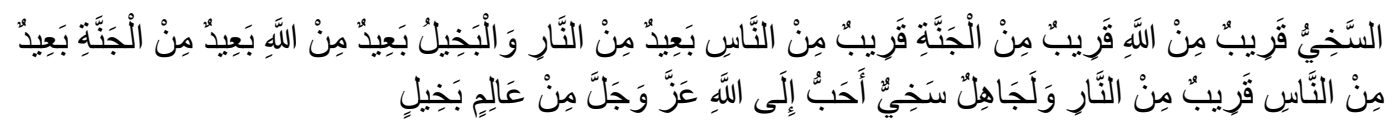

"Orang yang dermawan (al-sakhi) itu dekat dengan Allah, dekat dengan surga, dekat dengan manusia, dan jauh dari neraka. Sedangkan orang yang pelit (al-bakhil) itu jauh dari Allah, jauh dari surga, jauh dari manusia, dan dekat dengan neraka. Orang bodoh yang dermawan lebih dicintai Allah ketimbang ahli ibadah yang pelit."

Seorang muslim senantiasa khawatir dengan nasibnya kelak di akhirat, sebab di hari kiamat nanti manusia akan dibangkitkan kembali dan dikumpulkan di padang mahsyar untuk mempertanggung jawabkan perbuatannya selama di dunia. Maka dari itu, Nabi saw memberi tahu kepada umatnya apa-apa yang bila di kerjakan di dunia dapat menjadi naungan di akhirat kelak. Salah satunya adalah banyak bersedekah atau berderma, sebagaimana yang Ia sampaikan dalam hadisnya:

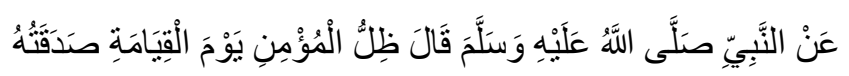

"Naungan orang beriman di hari Kiamat adalah sedekahnya" (HR Ahmad)

Maka kita mengetahui bahwa sedekah dapat menaungi kita di hari kiamat nanti. Sungguh beruntung orang beriman yang senantiasa mengeluarkan sedekah sebagai bentuk investasi cerdas untuk melindungi dirinya di hari yang sangat menakutkan bagi kebanyakan manusia. Maka dari itu jangan pernah memandang remeh sedekah yang engkau keluarkan kepada orang lain, sebab bukan karena banyaknya sedekah yang kita keluarkan namun lihatlah manfaat yang dihasilkannya (Naya, 2014). Berdasarkan uraian diatas maka penerapan sikap dermawan menurut hadis adalah melalui menerapkan latihan pembiasaan dalam bentuk kegiatan seperti membantu orang lain, bersedekah, bakti sosial, menyelenggarakan panitia zakat, dan pembiasaan mengisi kas dan infaq (Maulana, 2016).

\section{Kesimpulan}

Islam adalah agama yang sempurna. Tak hanya mengatur tentang bagaimana seharusnya hubungan manusia dengan Allah tetapi juga mengatur tentang bagaimana hubungan manusia dengan sesama manusia, yang harus dilakukan secara baik, benar dan seimbang. Salah satu ajaran 
Islam yang diperintahkan Allah kepada umatnya adalah peduli dan berderma. Orang yang suka berderma adalah orang yang benar pengakuan imannya. Berderma itu bukan perbuatan buruk, melainkan sebaliknya yakni perbuatan terpuji. Untuk bisa melaksanakan perintah berderma, tidak cukup hanya mengetahui teologinya saja, juga harus dibarengi dengan praktek pembiasaan dalam bentuk zakat, infak, sedekah, hibah, wasiat dan juga wakaf. Orang yang gemar mensedekahkan hartanya di jalan Allah tidak akan mengalami kerugian sedikitpun. Orang dermawan itu banyak dicintai manusia di dunia, dicintai Allah, dekat dengan surga, dan jauh dari neraka. Diharapkan penelitian ini memiliki manfaat bagi pengembangan khazanah pengetahuan Islam. Diakui penelitian ini memiliki keterbatasan dalam penyusunan kerangka berpikir dalam pembahasan konsep kedermawanan menurut hadis, penggunaan jenis penelitian, dan penerapan analisis yang lebih tepat. Penelitian ini merekomendasikan pentingnya menerapkan sikap dermawan karena kedermawanan merupakan sikap terpuji dan dicintai oleh Allah.

\section{Referensi}

Al-Asy'ari, A. (2018). Peningkatan sikap dermawan dalam perspektif Imam Al-Ghazali. 78-100.

Amar, F. (2017). Implementasi Filantropi Islam di Indonesia. Jurnal Ekonomi Syariah dan Filantropi Islam, 11-12.

Darmalaksana, W. (2020). Formula Penelitian Pengalaman Kelas Menulis. Jurnal Kelas Menulis UIN Sunan Gunung Djati Bandung. Retrieved from http://digilib.uinsgd.ac.id/32620/

Darmalaksana, W. (2020). Prosiding Proses Bisnis Validitas Hadis untuk Perancangan Aplikasi Metode Tahrij. Jurnal Ushuluddin UIN Sunan Gunung Djati Bandung, 1, 1-7.

Darmalaksana, W. (2020). Metode Penelitian Kualitatif Studi Pustaka dan Studi Lapangan. 1-5.

Maulana, F. (2016). Penanaman Nilai-Nilai Kedermawanan dalam Kegiatan

Organisasi IPNU Di Ranting Sampang Kecamatan Sampang. 12-13.

Naya, F. (2014). Sakha' dalam Perspektif Hadis. Ushuluddin, 174-175.

Nofiaturrahmah, F. (2018). Penanaman Karakter Dermawan Melalui Sedekah. 314-315.

Purwokerto, D. I. S. D. A. A., \& Zuhdy, I. (2017). Jurusan Pendidikan Agama Islam Pengembangan Sikap Dermawan Pada Siswa Di Sd Al-Irsyad AlIslamiyyah 01 Purwokerto. 